\title{
SOCIAL EXCLUSION AND HIGH SPEED RAIL: THE CASE STUDY OF SPAIN
}

\author{
Francesca Pagliara and Fabrizio Menicocci \\ Department of Civil, Architectural and Environmental Engineering - University of Naples \\ Federico II \\ José Manuel Vassallo and Juan Gomez \\ Centro de Investigación del Transporte (TRANSyT), Universidad Politécnica de Madrid
}

\section{SUMMARY}

Very few contributions in the literature have dealt with the issue of social exclusion related to High Speed Rail systems. The objective of this manuscript is to understand what are the factors excluding users from choosing High Speed Rail services considering as case study Spain. For this purpose, a Revealed Preference survey was employed in November and December 2015. A questionnaire was submitted to users of the Spanish transport systems travelling for long distance-journeys. The aim was that of investigating their perception of High Speed Rail system and the factors inhibiting passengers or excluding them from its use. Data about their socioeconomic characteristics were collected as well.

The main result of the survey has been that a relationship between social exclusion and High Speed Rail in Spain is present, especially in terms of geographical exclusion.

Key words: Social exclusion, High Speed Rail, accessibility, geographical exclusion.

\section{HIGH SPEED RAIL AND SOCIAL EXCLUSION}

Social exclusion "refers to the dynamic process of being shut out, fully or partially, from any of the social, economic, political and cultural systems which determine the social integration of a person in society" (Walker and Walker, 1997).

In the literature different approaches have been proposed to solve the problem of social exclusion related to transport systems. Firstly, transport systems planning should be integrated with urban and social policies. One first step towards the reduction of social exclusion might be that of promoting activities to increase accessibility.

Several contributions, on the effects brought by High Speed Rail (HSR) systems, have been analyzed in the literature (Vickerman, 1997; Preston and Wall, 2008; Pagliara et al., 2015a). However the question of social exclusion, related to them, still remains less analyzed with the exception of very few case studies (Pagliara et al., 2015b; Pagliara et al., 2015c).

The objective of this contribution is to understand the factors excluding users from choosing HSR services and the case study of Spain will be considered.

Technological developments and extensions of railway networks have been significant in 
the last decades (Campos et al., 2007). In 2015 there were almost $30000 \mathrm{~km}$ of HSR lines operating around the world, whereof more than $2500 \mathrm{~km}$ only in Spain, whose aim is to reach $10000 \mathrm{~km}$ in the near future. The first operating line in Spain is the one that connects Madrid to Sevilla and was opened in 1992. Many other lines have been introduced, above all in the southeast area of the Iberian Peninsula.

If on one hand it is clear that higher efficiency and better performances (above all for whatever concerns to travel time and connected operations) are making HSR the first choice for average-long trips, on the other is equally evident that prices often directed to a limited category of users and insufficient lines in specific areas, implicate a restriction for the users. This result brings an increase of social exclusion for them who are not available to use it, given that transport policy has a big impact on human quality of life (Jones and Lucas, 2012).

A lack of accessibility prevents people to "seize" better job opportunities, participate to community events and other public activities (Kenyon et al., 2003) or to be reached by other potential users (Cascetta, 2009).

The methodology proposed in this paper is reported in section 2, while conclusions and further perspectives are described in section 3 .

\section{THE METHODOLOGY}

This contribution is based on the framework of factors that may limit the mobility of socially excluded people, proposed by Church et al. (2000). The categories of exclusion connected to transport that they proposed are in the following reported:

1. Physical exclusion: physical barriers, i.e. lack of disabled facilities or of timetable information, limiting accessibility to transport services.

2. Geographical exclusion prevents people from accessing transport services, especially those living in rural areas or on peripheral urban estates.

3. By Exclusion from facilities it is meant the low accessibility connected with facilities, like shops, schools, health care or leisure services.

4. Economic exclusion represents the high monetary costs of travel preventing or inhibiting access to facilities or employment and thus having an impact on incomes.

5. Time-based exclusion refers to other demands on time, like combined work, household and child-care duties, reducing the time available for travel.

6. Fear-based exclusion refers to the fears for personal safety precluding the use of public spaces and/or transport services.

7. Space exclusion is the security or space management preventing given groups having access to public spaces, like first class waiting rooms at stations.

Starting from this premise a Revealed Preference (RP) survey was carried out between November and December 2015. The questionnaire was created on the Google platform and 414 useful ones were collected. Users were interviewed, travelling from and to different 
parts of Spain by different transport modes, including HSR.

Due to the survey method used, based on the web platform, the sample needed to be weighted. The percentages of gender and age classes, based on the 2011 Spanish Census (Instituto Nacional de Estadística, INE (www.ine.es), have been considered to adjust the sample. Then trips, between origin and destination less than $80 \mathrm{Km}$, have been removed from data base since they are classical regional trips not serviced by HSR. In this case the authors tried to avoid any bias present in the data set used to make inferences.

The main outcome of the survey is that users are mainly Spanish residents $(94.1 \%)$, aged between 50-64 years old (22.1\%), who are employed (63\%) with a monthly income between 1,000-2,000 Euros (38.5\%). The main trip purpose is personal affairs $(51.1 \%)$, followed by leisure trips $(33.0 \%)$.

In Table 1, the transport mode chosen has been reported. It follows that HSR is the most used transport mode, followed by car.

\begin{tabular}{|l|l|}
\hline Transport Mode & $\%$ \\
\hline Bus & $13.31 \%$ \\
\hline National Rail & $3.96 \%$ \\
\hline HSR & $47.10 \%$ \\
\hline Car & $31.56 \%$ \\
\hline Plane & $4.07 \%$ \\
\hline Total & $100 \%$ \\
\hline
\end{tabular}

Table 1 - Transport mode

In Table 2 there is the distinction between HSR users and non-users by the trip purposes. The majority of those who have travelled with HSR has gone on holiday, while non-users have moved mostly for personal reasons.

\begin{tabular}{|l|l|l|}
\hline Trip purpose & HSR Users & Non-HSR Users \\
\hline Work & $15.85 \%$ & $4.81 \%$ \\
\hline Study & $4.26 \%$ & $0.94 \%$ \\
\hline Holiday & $43.93 \%$ & $33.00 \%$ \\
\hline Personal activities & $35.97 \%$ & $61.24 \%$ \\
\hline Total & $100 \%$ & $100 \%$ \\
\hline
\end{tabular}

Table 2 - Trip purpose vs type of users

The different transport modes have been considered according to the household monthly income as reported in Table 3. High Speed Rail has been the most used alternative for those with a medium income, while the others have preferred the car. 


\begin{tabular}{|l|l|l|l|}
\cline { 2 - 4 } \multicolumn{1}{c|}{} & $\begin{array}{l}\text { Low } \\
(<€ 2,000)\end{array}$ & $\begin{array}{l}\text { Medium } \\
(€ 2,000-€ 4,000)\end{array}$ & $\begin{array}{l}\text { High } \\
(>€ 4,000)\end{array}$ \\
\hline Bus & $7.53 \%$ & $3.61 \%$ & $0.00 \%$ \\
\hline $\begin{array}{l}\text { National } \\
\text { Rail }\end{array}$ & $2.55 \%$ & $5.42 \%$ & $0.67 \%$ \\
\hline HSR & $13.21 \%$ & $22.97 \%$ & $3.83 \%$ \\
\hline Car & $17.69 \%$ & $14.96 \%$ & $4.99 \%$ \\
\hline Plane & $0.49 \%$ & $1.52 \%$ & $0.54 \%$ \\
\hline
\end{tabular}

\section{Table 3 - Transport mode vs household monthly income}

In Table 4, the choice among the 7 Church et al.'s categories of social exclusion has been analysed. Specifically respondents were asked to rank from 1 to 5 according to their perception of each factor of exclusion. For example, 5 was assigned by those who perceived the variable very inhibiting, 1 otherwise. In the following Table only 1 and 2 votes have been considered. Time-based exclusion turned out to be the most excluding factor.

\begin{tabular}{|l|c|c|c|l|l|l|}
\hline Economic & $\begin{array}{c}\text { Time- } \\
\text { based }\end{array}$ & Spatial & $\begin{array}{c}\text { Fear- } \\
\text { based }\end{array}$ & Geographical & Physical & Facilities \\
\hline $18.59 \%$ & $84.66 \%$ & $75.61 \%$ & $58.46 \%$ & $33.87 \%$ & $79.80 \%$ & $73.90 \%$ \\
\hline
\end{tabular}

\section{Table 4 - Church's categories of social exclusion of the sample}

As can be seen in Table 5, socioeconomic characteristics for non HSR users are not very different from figures reported for the whole sample. Additionally, by following the same approach of Table 4, Table 6 displays the factors to which users have given votes 4 and 5 . Geographical and, even more, economic exclusion have turned out to be inhibiting users from HSR and therefore they have been the fundamental reasons for not choosing it. Furthermore, Tables 7 and 8 show the categories of social exclusion and their relation to both trip purpose and household monthly income. 


\begin{tabular}{|c|c|c|}
\hline Characteristics & Levels & Sample \\
\hline \multirow{6}{*}{ Age } & $18-19$ & $9.18 \%$ \\
\hline & $20-29$ & $10.13 \%$ \\
\hline & $30-39$ & $13.61 \%$ \\
\hline & $40-49$ & $16.60 \%$ \\
\hline & $50-64$ & $23.76 \%$ \\
\hline & $>65$ & $26.87 \%$ \\
\hline \multirow{2}{*}{ Gender } & $\mathrm{M}$ & $48.02 \%$ \\
\hline & $\mathrm{F}$ & $51.98 \%$ \\
\hline \multirow{2}{*}{ Nationality } & Spanish & $97.21 \%$ \\
\hline & Others & $2.79 \%$ \\
\hline \multirow{2}{*}{ Education } & Degree or more & $73.48 \%$ \\
\hline & Others & $26.52 \%$ \\
\hline \multirow{5}{*}{ Occupation } & $\begin{array}{l}\text { Full time/part time } \\
\text { worker }\end{array}$ & $56.71 \%$ \\
\hline & Student & $12.50 \%$ \\
\hline & Unemployed & $2.00 \%$ \\
\hline & Freelance & $1.97 \%$ \\
\hline & Retired & $26.83 \%$ \\
\hline \multirow{6}{*}{$\begin{array}{l}\text { Monthly } \\
\text { income }\end{array}$} & $<€ 1000$ & $2.70 \%$ \\
\hline & $€ 1000-€ 2000$ & $44.41 \%$ \\
\hline & $€ 2000-€ 3000$ & $30.95 \%$ \\
\hline & $€ 3000-€ 4000$ & $11.60 \%$ \\
\hline & $€ 4000-€ 5000$ & $7.09 \%$ \\
\hline & $>€ 5000$ & $3.25 \%$ \\
\hline \multirow{4}{*}{ Trip purpose } & Work & $4.81 \%$ \\
\hline & Study & $0.94 \%$ \\
\hline & Holiday & $33.00 \%$ \\
\hline & Personal activities & $61.24 \%$ \\
\hline \multirow{5}{*}{ Travel type } & Alone & $31.67 \%$ \\
\hline & Partner & $39.58 \%$ \\
\hline & Colleagues & $0.00 \%$ \\
\hline & Friends & $15.07 \%$ \\
\hline & Relatives & $13.68 \%$ \\
\hline
\end{tabular}

Table 5 - Socioeconomic characteristics of non-HSR users 


\begin{tabular}{|l|l|l|l|l|l|l|}
\hline Economic & $\begin{array}{c}\text { Time- } \\
\text { based } \\
\text { exclusion }\end{array}$ & $\begin{array}{c}\text { Spatial } \\
\text { exclusion }\end{array}$ & $\begin{array}{c}\text { Fear- } \\
\text { based } \\
\text { exclusion }\end{array}$ & Geographical & Physical & Facilities \\
\hline $85.17 \%$ & $37.87 \%$ & $13.40 \%$ & $2.63 \%$ & $51.00 \%$ & $20.83 \%$ & $18.03 \%$ \\
\hline
\end{tabular}

Table 6 - Church's categories of social exclusion (non HSR-users)

\begin{tabular}{|l|l|l|l|l|l|l|l|}
\hline \multirow{2}{*}{$\begin{array}{c}\text { Trip } \\
\text { purpose }\end{array}$} & \multicolumn{7}{|c|}{ Categories of Exclusion } \\
\cline { 2 - 8 } & Economic & $\begin{array}{c}\text { Time- } \\
\text { based }\end{array}$ & Spatial & $\begin{array}{c}\text { Fear- } \\
\text { based }\end{array}$ & Geographical & Physical & Facilities \\
\hline Work & $3.81 \%$ & $0.00 \%$ & $0.00 \%$ & $0.00 \%$ & $2.80 \%$ & $0.00 \%$ & $0.00 \%$ \\
\hline Study & $0.85 \%$ & $0.64 \%$ & $0.40 \%$ & $0.00 \%$ & $0.00 \%$ & $0.55 \%$ & $0.55 \%$ \\
\hline Holiday & $30.01 \%$ & $2.65 \%$ & $3.23 \%$ & $0.85 \%$ & $22.70 \%$ & $4.90 \%$ & $4.12 \%$ \\
\hline $\begin{array}{l}\text { Personal } \\
\text { activities }\end{array}$ & $50.50 \%$ & $19.35 \%$ & $9.77 \%$ & $1.78 \%$ & $25.50 \%$ & $15.39 \%$ & $13.36 \%$ \\
\hline
\end{tabular}

Table 7 - Church et al.'s categories of social exclusion vs trip purpose (non-HSR users)

\begin{tabular}{|c|c|c|c|c|c|c|c|}
\hline \multirow{2}{*}{$\begin{array}{l}\text { Monthly } \\
\text { income }\end{array}$} & \multicolumn{7}{|c|}{ Categories of Exclusion } \\
\hline & Economic & $\begin{array}{l}\text { Time- } \\
\text { based }\end{array}$ & Spatial & $\begin{array}{l}\text { Fear- } \\
\text { based }\end{array}$ & Geographical & Physical & Facilities \\
\hline $\begin{array}{l}\text { Low } \\
\text { and } \\
\text { medium }\end{array}$ & $66.40 \%$ & $21.06 \%$ & $9.03 \%$ & $1.50 \%$ & $37.66 \%$ & $14.45 \%$ & $10.01 \%$ \\
\hline High & $18.77 \%$ & $1.58 \%$ & $4.37 \%$ & $1.12 \%$ & $13.34 \%$ & $6.38 \%$ & $8.02 \%$ \\
\hline
\end{tabular}

Table 8 - Church et al.'s categories of social exclusion vs household monthly income (non-HSR users)

Those who travelled for holiday or for personal reasons and have a lower income are the ones who have been mainly excluded from HSR because of economic and geographical categories. After all, these two often coexist, considering that those who have limited financial resources are also unable to live close to areas accessible to HSR services.

\section{CONCLUSIONS}

As it could be expected, HSR system has been the most used transport mode for averagelong distance trips. Indeed, as stated before, the Spanish railway network is the longest one in Europe and guarantees remarkable performances. This means that the average Spanish user has generally a positive approach with respect to HSR. However but it cannot be forgotten the result of Church et al.'s categories of social exclusion. Geographical and, even more, economic exclusion have a significant impact in limiting users. 
In the future works should take into account the implementation of the railway network for increasing accessibility and therefore reducing geographical exclusion.

Further perspectives will consider the calibration of a mode choice model, taking into account a choice set definition model of the alternatives considering the seven Church et al.'s criteria of social exclusion.

\section{REFERENCES}

CASCETTA, E. (2009). Transportation Systems Analysis: Models and Applications. Springer, New York.

CAMPOS, J., DE RUS, G. and BARRON, I. (2007). A review of HSR experiences around the world, Munich.Personal RePEc Archive, paper no. 38669.

CHURCH, A., FROST, M. and SULLIVAN, K. (2000). Transport and social exclusion in London. Transport Policy 7, pp. 195-205.

JONES, P. and LUCAS, K. (2012). The social consequences of transport decision-making: clarifying concepts, synthesizing knowledge and assessing implications. Journal of Transport Geography 21, pp. 4-16.

KENYON, S., LYONS, G. and RAFFERTY, J. (2003). Transport and social exclusion: investigating the possibility of promoting inclusion through virtual mobility. Journal of Transport Geography 10, pp. 207-219.

PAGLIARA, F., LA PIETRA, A., GOMEZ, J. and VASSALLO, J. M. (2015a). High Speed Rail and the tourism market: evidence from the Madrid case study. Transport Policy 37, pp.187-194.

PAGLIARA, F., BIGGIERO, L. and FUSCO, M. (2015b). A mode choice model for evaluating social exclusion from High Speed Rail. Submitted to Socioeconomic Planning Sciences.

PAGLIARA, F., DE POMPEIS, V. and PRESTON, J. (2016c). Travel cost: not always the most important element of social exclusion. Paper to be presented at the WCTR conference, Shanghai, 10-15th July.

PRESTON, J. and WALL, G. (2008). The Ex-ante and Ex-post Economic and Social Impacts of the Introduction of High-speed Trains in South East England. Planning Practice \& Research 23, pp. 403-422.

VICKERMAN, R. (1997). High Speed rail in Europe: experiences and issues for future developments. The Annals of Regional Science 31, pp. 21-38.

WALKER, A. and WALKER, C. (1997) Britain Divided: The Growth of Social Exclusion in the 1980s and 1990s. CPAG, London. 